\title{
GIÁ TRỊ CỦA CỌNG HƯỞNG TỪ TRONG DỰ ĐOÁN ĐỌ MÔ HỌC CỦA U MÀNG NÃO VÙNG GÓC CẦU TIÉU NÃO
}

\author{
Nguyễn Duy Hùng ${ }^{1,2}$ và Vương Kim Ngân ${ }^{3, 凶}$ \\ ${ }^{1}$ Trường Đại học Y Hà Nội \\ ${ }^{2} B$ ệnh viện Hũu nghị Việt Đức \\ ${ }^{3}$ Bệnh viện Đa khoa Quốc tế Vinmec Times City
}

Vai trò của cộng hưởng từ trong dụ̣ đoán độ mô học của u màng não vùng góc cầu tiểu não. Phương pháp hồi cứu trên 46 bệnh nhân u màng não vùng góc cầu tiểu não được chụp cộng hưởng từ, phẫu thuật và có kết quả giải phẫu bệnh sau phẫu thuật tại Bệnh viện Việt Đức từ tháng 8 năm 2019 đến tháng 6 năm 2020. Giá trị của $A D C$ vùng u, các dấu hiệu dụ̂ đoán u màng bậc cao trên cộng hưởng từ được mô tả, thống kê và đối chiếu với độ mô học trên hình ảnh giải phẫu bệnh. Kết quả: các u màng não có dấu hiệu hạn chế khuếch tán, ngấm thuốc không đồng nhất sau tiêm, viền dịch não tủy quanh u không đều, phù não xung quanh u, giới hạn u không rõ và xâm lấn cấu trúc lân cận trên hình ảnh cộng hưởng từ có khả năng được chẩn đoán là u màng não bậc cao trên mô bệnh học cao gấp lần lượt là 19; 10,8; 14,2; 14,2; 12 , 3 và 78 lần so với các u màng não không có dấu hiệu này. Giá trị $A D C$ trung bình và rADC u màng não bậc I cao hơn giá trị $A D C$ trung bình và $r A D C$ u màng não không phải bậc I. Ngương giá trị $r A D C$ lớn hơn hoặc bằng 1,0 có ý nghĩa dự báo tốt đối với u màng não bậc I. Kết luận: Các dấu hiệu trên cộng hưởng từ và giá trị $A D C$ có vai trò dụ̂ đoán độ mô học của u màng não.

Từ khóa: u màng não, góc cầu tiểu não, cộng hưởng từ, phân độ mô học.

\section{I. ĐẠT VẤN ĐÊ}

U màng não chiếm khoảng 20 - 30\% các khối u nội sọ. $U$ màng não ở góc cầu tiểu não chiếm 5 - 10\% trong số u màng não nội sọ và đứng hàng gặp thứ hai, sau u dây thần kinh VIII, chiếm khoảng 5-12\% các khối u góc cầu tiểu não. ${ }^{1,2} U$ màng não xuất phát từ các tế bào màng nhện, thường gặp ở lứa tuổi trung niên, tần suất gặp ở nữ gấp đôi ở nam. ${ }^{3}$ Theo phân loại của Tổ chức y tế thế giới phần lớn u màng não là tổn thương lành tính, tiến triển chẩm - WHO độ I, nhưng có một tỷ lệ nhỏ u màng não không điển hình, $u$ màng não ác tính với độ mô học cao - WHO độ II, III có liên quan tới nguy cơ tái phát sau phẫu thuật.

Tác giả liên hệ: Vương Kim Ngân

Bệnh viện Đa khoa Quốc tế Vinmec Times City

Email: drkimngan.rad@gmail.com

Ngày nhận: 22/02/2021

Ngày được chấp nhận: 29/03/2021
Việc dự đoán độ mô học của u màng não trước phẫu thuật giúp phẫu thuật viên có thể lên phương án điều trị tốt hơn trong việc tính toán thời gian phẫu thuật, phác đồ điều trị hóa chất bổ trợ và tiên lượng nguy cơ tái phát sau điều trị. ${ }^{3}$ Cộng hưởng từ (Magnetic resonance imaging - MRI) có vai trò quan trọng, là tiêu chuẩn vàng trong chẩn đoán xác định u màng não góc cầu tiểu não, kích thước, đặc điểm xâm lấn, chèn ép các cấu trúc lân cận, các dây thần kinh cũng như dự đoán độ mô học của tổn thương dựa trên một số đặc điểm hình ảnh trên cộng hưởng từ để lên phương án điều trị và tiên lượng trước phẫu thuật. ${ }^{1,3,4}$ Theo một số nghiên cứu trước trên thế giới, một số đặc điểm hình ảnh có thể được sử dụng để dự đoán độ mô học của u màng não bao gồm mất giới hạn với nhu mô não lân cận, phù não xung quanh $u$, đường bờ không đều, hạn chế 
khuếch tán trên chuỗi xung diffusion và ngấm thuốc không đồng nhất. ${ }^{5}$ Hiện tại ở Việt Nam chưa có nghiên cứu nào về liên quan giữa đặc điểm hình ảnh và phân độ mô bệnh học của u màng não, đặc biệt u màng não vùng góc cầu tiểu não. Vì vậy chúng tôi tiến hành để đánh giá mối liên quan của các đặc điểm hình ảnh trên cộng hưởng từ và phân độ mô bệnh học của u màng não vùng góc cầu tiểu não.

\section{II. ĐÓl TƯợNG VÀ PHƯO'NG PHÁP}

\section{1. Đối tượng}

Những bệnh nhận được chụp cộng hưởng từ sọ não có chẩn đoán u màng não vùng góc cầu tiểu não, được phẫu thuật và có kết quả giải phẫu bệnh sau mổ tại Bệnh viện Hữu Nghị Việt Đức trong khoảng thời gian từ tháng 8 năm 2019 đến tháng 6 năm 2020.

\section{Phương pháp}

Nghiên cứu hồi cứu mô tả.

Kỹ thuật chụp cộng hưởng từ sọ não được thực hiện thống nhất theo quy trình của khoa Chẩn đoán hình ảnh Bệnh viện Hữu nghị Việt Đức.

Kỹ thuật chụp cộng hưởng từ sọ não u góc cầu tiểu não được thực hiện trên hệ thống máy cộng hưởng từ 1,5Tesla của hãng Philips Healthcare và hãng Siemens Healthcare, với protocol:

Localize 3 mặt phẳng

Sagital T1 TSE

Axial T2 FLAIR

Axial T2 TSE

Coronal T2 TSE

Axial DWI b0 và b1000, có tái dựng bản đồ ADC

Axial T2 ciss 3D

Axial T2*

Axial T1 FS trước tiêm và Axial T1 3D sau tiêm thuốc đối quang từ với liều lượng $0,1 \mathrm{mmol} /$ $\mathrm{kg}$ tức $0,2 \mathrm{ml} / \mathrm{kg}$.

Quy trình, phương pháp thu thập số liệu
Các bác sĩ chẩn đoán hình ảnh của nhóm nghiên cứu đọc hồi cứu tất cả phim chụp của bệnh nhân trên hệ thống phần mềm phần mềm Infinitt, kết quả đọc độc lập với kết quả giải phẫu mô bệnh học. Các dấu hiệu đặc điểm u màng não bậc bao gồm tín hiệu trên DWI(ADC), ngấm thuốc sau tiêm (đồng nhất, không đồng nhất), viền dịch não tủy quanh u (đều, không đều), phù não xung quanh u, giới hạn khối (rõ, không rõ), dấu hiệu hoại tử bên trong u và xâm lấn cấu trúc lân cận được ghi nhận. Hạn chế khuếch tán khi tín hiệu của khối u ở trên b1000 cao hơn nhu mô não bình thường với $A D C$ giảm. Viền dịch não tủy quanh $u$ được quan sát trên ảnh T2W. Phù não xung quanh u là tăng tín hiệu của nhu mô não xung quanh u trên ảnh T2W hoặc FLAIR. Dấu hiệu hoại tử trong u khi bên trong u có thành phần tín hiệu dạng dịch, không ngấm thuốc sau tiêm. Xâm lấn các cấu trúc lân cận như động mạch, xoang tĩnh mạch, thần kinh hoặc xâm lấn xương lân cận. ${ }^{5}$

Đo hệ số khuyếch tán trực tiếp ở vùng $u$ trên ảnh bản đồ $A D C$ theo nhóm u bậc I và nhóm u không phải bậc I với diện tích ROI trung bình từ 10 đến $20 \mathrm{~mm}^{2}$. Trong trường hợp khối u không đồng nhất hoặc kích thước quá nhỏ chúng tôi có thể sử dụng ROI nhỏ hơn. Khi đặt ROI, không đặt vào các vùng xuất huyết, ngấm vôi, mạch máu, hoại tử... Tiến hành đo tại vị trí u trên ảnh bản đồ $A D C$ với 3 điểm ở các vùng có tín hiệu thấp nhất (màu tối) và không trùng nhau. Tính giá trị trung bình $A D C$ của vùng $u$. $V$. Dùng đường cong $R O C$ để dự báo giá trị của hệ số khuyếch tán trong chẩn đoán phân biệt nhóm u bậc 1 và nhóm u không phải bậc 1 , từ đó tính độ nhạy, độ đặc hiệu, giá trị dự báo dương tính, giá trị dự báo âm tính, diện tích dưới đường cong.

\section{Xử lí số liệu}

Các số liệu được thu thập theo mẫu bệnh 
án nghiên cứu xử lý bằng phần mềm SPSS 22.0 (SPSS, Inc., Chicago, IL, USA) với các thuật toán mô tả tính trung bình, độ lệch chuẩn, tính tỷ lệ phần trăm.

So sánh tỷ lệ giữa các các nhóm trong nghiên cứu bằng thuật toán $\chi^{2}$ với độ tin cậy $95 \%$.

Phân tích đơn biến: đánh giá mối liên quan giữa biến phụ thuộc (kết quả) và biến độc lập (biến tác động). Xác định tỷ xuất chênh (OR), khoảng tin cậy $(\mathrm{Cl})$ và mức ý nghĩa.

\section{4. Đạo đức nghiên cứu}

Các thông tin về hồ sơ bệnh án và hình ảnh được chúng tôi bảo mật và chỉ được sử dụng cho mục đích nghiên cứu.

\section{KÉT QUẢ}

Trong thời gian nghiên cứu, trong số 46 bệnh nhân u màng não góc cầu tiểu não có 41 bệnh nhân u màng não bậc I, 5 bệnh nhân u màng não không phải bậc I. Các đặc điểm hình ảnh trên cộng hưởng từ dự đoán u màng não bậc cao được trình bày ở bảng 1 . U màng não góc cầu tiểu não có các dấu hiệu: hạn chế khuếch tán, ngấm thuốc không đồng nhất sau tiêm, viền dịch não tủy quanh u không đều, phù não xung quanh u, giới hạn u không rõ và xâm lấn cấu trúc lân cận có khả năng được chẩn đoán là u màng não bậc cao trên mô bệnh học cao gấp lần lượt là 19; 10,8; 14,2; 14,2; 12,3 và 78 lần so với các u màng não không có dấu hiệu này với giá trị $p<0,05$ có ý nghĩa thống kê. Dấu hiệu hoại tử trong u có tương quan không có ý nghĩa thống kê với $p>0,05$ trong dự đoán u màng não bậc cao.

Giá trị $A D C$ trung bình và tỷ lệ rADC của nhóm u màng não bậc I và không phải bậc I được trình bày ở bảng 2. Giá trị $A D C$ trung bình và rADC u màng não bậc I cao hơn giá trị $A D C$ trung bình và $\mathrm{rADC}$ u màng não không phải bậc I. Sự khác biệt có ý nghĩa thống kê với $p$ lần lượt là $p$ $<0,001$ và 0,042 .

Đường cong ROC tìm giá trị ngưỡng rADC được mô tả ở hình 1. Diện tích dưới đường cong của giá trị rADC là $0,88(95 \% \mathrm{Cl}: 0,75-1,0)$, giá trị tiên lượng sớm các trường hợp bệnh nhân u màng não bậc I ở mức tốt. Tại điểm cắt là 1,0 có độ nhạy và độ đặc hiệu lớn nhất. Độ nhạy bằng $88,0 \%$ và độ đặc hiệu là 80,0\%.

Bảng 1. Phân tích tương quan giữa các đặc điểm trên cộng hưởng từ trong dự đoán u màng não góc cầu tiểu não không phải bậc I

\begin{tabular}{ccccc}
\hline \multirow{2}{*}{ Đặc điểm } & OR & \multicolumn{2}{c}{$\mathbf{9 5 \%} \mathbf{C I}$ của OR } & \multirow{2}{*}{ p-value } \\
\cline { 3 - 4 } & & Giới hạn dưới & Giới hạn trên & \\
\hline Hạn chế khuếch tán trên diffusion & 19 & 2,23 & 161,61 & 0,012 \\
\hline Ngấm thuốc không đều sau tiêm & 10,8 & 1,43 & 81,33 & 0,031 \\
\hline Viền dịch não tủy quanh u không đều & 14,2 & 1,41 & 143,70 & 0,006 \\
\hline Phù não xung quanh u & 14,2 & 1,41 & 143,70 & 0,006 \\
\hline Giới hạn không rõ & 12,3 & 1,25 & 121,30 & 0,011 \\
\hline Hoại tử trong u & 8,4 & 0,99 & 71,82 & 0,084 \\
\hline Xâm lấn cấu trúc lân cận & 78 & 5,72 & 1062 & $<0,001$ \\
\hline
\end{tabular}


Bảng 2. Giá trị $A D C$ trung bình vùng u $\left(\times 10^{-3} \mathrm{~mm}^{2} / \mathrm{s}\right)$ và $\mathrm{rADC}$

\begin{tabular}{cccc}
\hline U màng não & N & ADC vùng u & rADC \\
\hline Bậc I & 41 & $0,972 \pm 0,107$ & $1,18 \pm 0,24$ \\
\hline Không bậc I & 5 & $0,704 \pm 0,186$ & $0,94 \pm 0,26$ \\
\hline Tổng & 46 & $0,838 \pm 0,180$ & $1,08 \pm 0,24$ \\
\hline & & \\
\hline
\end{tabular}

Hình 1. Đường cong ROC tìm giá trị ngưỡng rADC của u màng não chẩn đoán u màng não bậc I và không phải bậc I

\section{BÀN LUẦN}

U màng não là khối u nội sọ lành tính thường gặp nhất, thường gặp ở bệnh nhân trong độ tuổi 50, hay gặp ở nữ hơn nam. Về mặt mô bệnh học, 80-90\% u màng não có độ mô học bậc I, trong đó dưới nhóm u biểu mô màng não hay gặp nhất. ${ }^{2}$ Dự đoán độ mô học của u màng não có ý nghĩa quan trọng trong việc định hướng điều trị trước phẫu thuật và đánh giá các yếu tố tiên lượng tái phát của u màng não sau phẫu thuật. ${ }^{5-7}$ Trong nghiên cứu của chúng tôi, các u màng não có dấu hiệu hạn chế khuếch tán, ngấm thuốc không đồng nhất, có viền dịch não tủy quanh u không đều, phù não xung quanh u, giới hạn của u không rõ và xâm lấn các cấu trúc lân cận có khả năng được chẩn đoán là u màng não bậc cao cao gấp lần lượt là 19; 10,8; 14,2; 14,2; 12,3 và 78 lần so với các u màng não không có dấu hiệu này với giá trị $p<0,05$ có ý nghĩa thống kê. Kết quả này tương tự với nghiên cứu trước đó của Liư trên 246 bệnh nhân về vai trong của MRI trong dự đoán bậc của u màng não, các dấu hiệu hạn chế khuếch tán trên diffusion, ngấm thuốc không đồng nhất sau tiêm, viền dịch não tủy quanh u không đều, phù não xung quanh $u$, giới hạn $u$ không rõ có giá trị OR lần lượt là 16,6; 6,1; 13,5; 9,1 và 6,2 với giá trị p có ý nghĩa thống kê. Các u màng não bậc cao đặc trưng bởi tăng số lượng tế bào $u$, tăng tỷ lệ u/bào tương, kích thước tế bào nhỏ với tăng quá trình nguyên phân do đó tăng hạn chế khuếch tán trên DWI. ${ }^{8,9}$

Các u màng não bậc cao thường có xu hướng xâm lấn trực tiếp nhu mô não lân cận với xâm lấn lớp tế bào màng nhện và phá hủy hàng rào máu não bình thường do đó u màng não bậc cao thường có đường bờ không đều, giới hạn không rõ và có phù nhu mô não lân cận xung quanh u. Phù não xung quanh u là một yếu tố chỉ ra việc khó lấy ra toàn bộ khối u trong phẫu thuật. Tuy nhiên một số u màng não bậc I có thể xuyên qua lớp dưới màng nuôi dẫn đến sự tắc nghẽn lưu thông làm cho đường bờ của tổn thương không đều cũng như thay đổi tín hiệu nhu mô não xung quanh. Vì vậy để dự báo bậc của khối u màng não cần kết hợp nhiều yếu tố. ${ }^{8,10}$ 
Dấu hiệu ngấm thuốc không đồng nhất sau tiêm ở u màng não bậc cao có thể do có hoại tử, chảy máu trong u hoặc do sự phân bố khác nhau của các tế bào với độ biệt hóa khác nhau. Tuy nhiên một số u màng não bậc I có thể có vôi hóa, biến đổi dạng nang bên trong đặc biệt khi u có kích thước lớn. ${ }^{8}$ Trong nghiên cứu của chúng tôi, dấu hiệu ngấm thuốc không đồng nhất có giá trị OR 10,8 với p có ý nghĩa thống kê trong khi đó dấu hiệu hoại tử trong u có tương quan OR không có ý nghĩa thống kê với $p>0,05$ trong dự đoán u màng não bậc cao. Dấu hiệu xâm lấn các cấu trúc lân cận là một dấu hiệu chỉ ra sự phát triển nhanh của khối u màng não bậc cao, trong nghiên cứu của chúng tôi, dấu hiệu này có giá trị OR cao nhất 78 với $p$ có nghĩa thống kê trong đó có 3 trường hợp xâm lấn mạch máu (động mạch thân nền và xoang tĩnh mạch) và 2 trường hợp xâm lấn xương lân cận. Theo nghiên cứu của Coroller $^{7}$ trên 175 bệnh nhân u màng não, dấu hiệu xâm lấn xoang tĩnh mạch và hoại tử có OR lần lượt 2,2 và 6,6 với $p$ có ý nghĩa thống kê trong dự báo u màng não bậc cao.

Trong nghiên cứu của chúng tôi, giá trị ADC trung bình của u màng não bậc I $(0,972 \pm 0,107$ $\mathrm{x} 10^{-3} \mathrm{~mm}^{2} / \mathrm{s}$ ) cao hơn giá trị ADC trung bình của u màng não không phải bậc I $(0,704 \pm 0,186$ x10${ }^{3} \mathrm{~mm}^{2} / \mathrm{s}$ ), sự khác biệt có ý nghĩa thống kê với $\mathrm{p}$ $<0,001$. Kết quả nghiên cứu phù hợp với nghiên cứu của Hwang, ${ }^{11}$ giá trị $A D C$ trung bình của nhóm u màng não bậc I $\left(0,93 \pm 0,03 \times 10^{-3} \mathrm{~mm}^{2} / \mathrm{s}\right)$ cao hơn của nhóm u màng não không bậc I $(0,79$ $\pm 0,03 \times 10^{-3} \mathrm{~mm}^{2} / \mathrm{s}$ ), sự khác biệt có ý nghĩa thống kê với $p=0,001$.

Giá trị rADC của nhóm u màng não bậc I $(1,18$ $\pm 0,24$ ) cao hơn giá trị rADC của nhóm u màng não không phải bậc I $(0,94 \pm 0,26)$ với sự khác biệt có ý nghĩa thống kê $p=0,042$. Giá trị rADC lớn hơn hoặc bằng 1 có khả năng dự báo tốt với các u màng não bậc 1 . Trên đường cong ROC, tại điểm cắt rADC là 1,0 có độ nhạy và độ đặc hiệu lớn nhất, với độ nhạy bằng 88,0\% và độ đặc hiệu là $80,0 \%$.

\section{KÉT LUẦN}

U màng não là khối u hay gặp chiếm thứ hai sau u dây VIII ở vị trí góc cầu tiểu não. Việc dự đoán bậc mô học của u màng não có ý nghĩa trong đánh giá khả năng phẫu thuật, tiên lượng khối u. Có các dấu hiệu trên hình ảnh cộng hưởng từ: hạn chế khuếch tán, ngấm thuốc không đồng nhất sau tiêm, viền dịch não tủy quanh u không đều, phù não xung quanh u, giới hạn u không rõ và xâm lấn cấu trúc lân cận, khối u có khả năng được chẩn đoán u màng não bậc cao trên mô bệnh học (OR) cao gấp 19; 10,8; 14,2; 14,2; 12,3 và 78 lần so với các u màng não không có dấu hiệu này với giá trị $p<0,05$ có ý nghĩa thống kê. Giá trị $A D C$ trung bình và $\mathrm{rADC}$ của u màng não góc cầu tiểu não bậc I cao hơn u màng não không phải bậc I. Ngưỡng rADC lớn hơn hoặc bằng 1 có giá trị trong dự đoán u màng não bậc I.

\section{TÀI LIẸU THAM KHẢO}

1. Meningiomas - Classifications, Risk Factors, Diagnosis and Treatment. American Association of Neurosurgical Surgeons. https:// www.aans.org/.

2. Gao K, Ma H, Cui Y, et al. Meningiomas of the Cerebellopontine Angle: Radiological Differences in Tumors with Internal Auditory Canal Involvement and Their Influence on Surgical Outcome. PLOS ONE. 2015;10(4):e0122949. doi:10.1371/journal. pone.0122949.

3. Alyamany M, Alshardan MM, Jamea AA, et al. Meningioma Consistency: Correlation Between Magnetic Resonance Imaging Characteristics, Operative Findings, and Histopathological Features. Asian J Neurosurg. 2018;13(2):324-328.doi:10.4103/17935482.228515 . 
4. Maaly MA, Sultan AA. Current role of MRI in cerebellopontine angle lesions. Menoufia Med J. 2016. 29(1):147-51. doi: 10.4103/11102098.179006.

5. Spille DC, Sporns PB, Heß K, et al. Prediction of High-Grade Histology and Recurrence in Meningiomas Using Routine Preoperative Magnetic Resonance Imaging: A Systematic Review. World Neurosurg. 2019;128:174-181. doi:10.1016/j. wneu.2019.05.017.

6. Karthigeyan M, Dhandapani S, Salunke $\mathrm{P}$, et al. The Predictive Value of Conventional Magnetic Resonance Imaging Sequences on Operative Findings and Histopathology of Intracranial Meningiomas: A Prospective Study. Neurol India. 2019;67(6):1439. doi:10.4103/0028-3886.273632.

7. Coroller TP, Bi WL, Huynh E, et al. Radiographic prediction of meningioma grade by semantic and radiomic features. PLOS ONE. 2017;12(11):e0187908. doi:10.1371/journal. pone.0187908.

8. Liu Y, Chotai S, Chen M, et al. Preoperative Radiologic Classification of Convexity Meningioma to Predict the Survival and Aggressive Meningioma Behavior. PLoS ONE. 2015;10(3). doi:10.1371/journal.pone.0118908.

9. Szafer A, Zhong J, Anderson Aw, et al. Diffusion-weighted imaging in tissues: theoretical models. NMR Biomed. 1995;8(78):289-96.

10. Tamiya $T$, Ono $Y$, Matsumota $K$, et al. Peritumoral brain edema in intracranial meningiomas: effects of radiological and histological factors. Neurosurgery. 2001;49(5):1046-51.

11. Hwang W, Marciscano AE, Kim D, et al. Correlation of Imaging Characteristics With Histopathological WHO Grade in Meningiomas. IJROBP. 2015;93(3):86. https://www.redjournal. org/article/S0360-3016(15)01496-0/pdf.

\section{Summary}

\section{VALUE OF MAGNETIC RESONANCE IMAGING IN PREDICTION THE HISTOPATHOLOGIC GRADE OF THE MENINGIOMAS OF THE CEREBELLOPONTINE ANGLE}

Purpose: This sudy aims to evaluate the value of magnetic resonance imaging (MRI) in the prediction of histopathologic grade of meningiomas of the cerebellopontine angle. Materials and method: The retrospective study was conducted on 46 patients with meningiomas of the cerebellopontine angle underwent MRI, surgery and had histopathologic report at the Viet Duc University Hospital from August 2019 to June 2020. On imaging, the signs of meningiomas and ADC were described, measured and compared with histopathologic reports. Results: restricted, heterogeneous enhancement, illdefined, peritumoral edema, irregular tumor shape and invading adjacent structure were significantly correlated with histopathologic grade. The existence of these results improved the likelihood of 19; 10.8; $14.2 ; 14.2 ; 12.3$ and 78-fold respectively. Grade I meningiomas showed higher ADC and rADC than those of non-grade I meningiomas. The rADC of over or at least 1,0 showed high predictation for grade 1 meningiomas. Conclusion: The characteristics and ADC measurement on MRI showed significant role in predicting the grade of meningiomas at the cerebellopontine angle.

Keywords: meningiomas, cereabellopontine angle, magnetic resonance imaging, histopathologic grade. 